\title{
Impact of host- and early treatment-related factors on mortality in ICU patients with candidemia: a bicentric retrospective observational study
}

\author{
Shingo Ohki ${ }^{1}$, Nobuaki Shime ${ }^{1 *} \mathbb{B}$, Tadashi Kosaka ${ }^{2}$ and Naohisa Fujita ${ }^{3}$
}

\begin{abstract}
Background: Candidemia is one of the most life-threatening infections among critically ill patients in the intensive care unit. However, the number of studies on the impact of host- and early treatment-related factors on mortality in this cohort is limited. The aim of this study was to investigate the relationship between clinically relevant factors, including early treatment (appropriate antifungal therapy and/or central venous catheter removal) and mortality in intensive care unit patients with candidemia.

Methods: We performed a retrospective observational study in two Japanese University hospitals between January 2007 and December 2016. Adult intensive care unit patients with candidemia who met the following inclusion criteria: (1) $\geq 18$ years old; (2) admitted in intensive care unit at the time of onset; and (3) central venous catheter in situ at the time of onset were included. We performed univariate and multivariate logistic regression analysis to identify factors associated with 30-day crude mortality.

Results: A total of 68 patients met the inclusion criteria, 47 (69\%) of whom were males. The median age was 68.0 (interquartile range, 61.0-76.0) years. The most common causative Candida species was Candida albicans (40 [59\%] patients). With respect to the source of infection, central venous catheter-related candidemia was the most frequent (30 [44\%] patients). Thirty-day crude mortality was 54\% (37 patients). In multivariate logistic regression analysis, Acute Physiology and Chronic Health Evaluation II score (1-point increments) was the only factor that was independently associated with higher 30-day crude mortality. Other variables, including appropriate antifungal therapy and/or central venous catheter removal $\leq 24 \mathrm{~h}$ and $\leq 48 \mathrm{~h}$ following onset, did not significantly influence mortality.

Conclusions: Candidemia in intensive care unit patients is still associated with high 30-day crude mortality rates. The only predictor of death was Acute Physiology and Chronic Health Evaluation II score $\leq 24 \mathrm{~h}$ following candidemia onset. Early empiric antifungal therapy and/or early CVC removal conferred no significant clinical benefit on survival in this patient population.
\end{abstract}

Keywords: Candida, Candidemia, Intensive care unit, Prognostic factor, Antifungal therapy, CVC removal, Mortality

\footnotetext{
* Correspondence: nshime@hiroshima-u.ac.jp

'Department of Emergency and Critical Care Medicine, Graduate School of Biomedical and Health Sciences, Hiroshima University, 1-2-3 Kasumi, Minami-ku, Hiroshima 734-8551, Japan

Full list of author information is available at the end of the article
}

(c) The Author(s). 2020 Open Access This article is licensed under a Creative Commons Attribution 4.0 International License, which permits use, sharing, adaptation, distribution and reproduction in any medium or format, as long as you give appropriate credit to the original author(s) and the source, provide a link to the Creative Commons licence, and indicate if changes were made. The images or other third party material in this article are included in the article's Creative Commons licence, unless indicated otherwise in a credit line to the material. If material is not included in the article's Creative Commons licence and your intended use is not permitted by statutory regulation or exceeds the permitted use, you will need to obtain permission directly from the copyright holder. To view a copy of this licence, visit http://creativecommons.org/licenses/by/4.0/ The Creative Commons Public Domain Dedication waiver (http://creativecommons.org/publicdomain/zero/1.0/) applies to the data made available in this article, unless otherwise stated in a credit line to the data. 


\section{Introduction}

Candida species are among the most common causative agents of nosocomial bloodstream infections [1]. In critically ill intensive care unit (ICU) patients, the incidence rate of Candida bloodstream infection (candidemia) is estimated at between 2.1 and 6.9 cases per 1000 ICU admissions [2-4], with a high crude mortality rate of 43$61 \%[2-5]$.

To date, many studies have investigated factors associated with mortality among candidemia patients across several clinical settings. However, most of the studies included non-ICU patients and therefore, little is known about prognostic factors in ICU patients with candidemia. Specifically, a limited number of studies have investigated the impact of early appropriate antifungal therapy and/or early removal of central venous catheter (CVC) on mortality, with inconsistent results [2-6].

Consequently, in this study, we investigated the relationship between clinically relevant factors, including early treatment (appropriate antifungal therapy and/or CVC removal) and mortality in ICU patients with candidemia.

\section{Methods}

\section{Study design and patient selection}

We conducted a bicentric, retrospective observational study in two university hospitals in Japan between January 2007 and December 2016. Participating hospitals included the Hiroshima University Hospital (746 beds) and the University Hospital, Kyoto Prefectural University of Medicine (1065 beds). We used the microbiological database of each participating hospital to identify positive blood cultures for Candida species. We included adult ICU patients with candidemia who met the following inclusion criteria: (1) were $\geq 18$ years old; (2) were admitted in the ICU at the time of onset; and (3) had a CVC in situ at the time of onset.

All data were anonymized, and the requirement for informed consent was waived due to the retrospective study design. This study was approved by the institutional review board of Hiroshima University (approval number: E-746) and Kyoto Prefectural University of Medicine (approval number: ERB-C-1162).

\section{Patient variables and outcomes}

The following information was collected from each patient's medical record for covariates: age at onset; sex; time from hospital admission to onset; Acute Physiology and Chronic Health Evaluation (APACHE) II score $\leq 24 \mathrm{~h}$ following onset; comorbidities and prior treatment exposure (solid organ malignancy $\leq 1$ year before onset, hematological malignancy $\leq 1$ year before onset, previous solid organ transplantation, previous hematopoietic stem cell transplantation, liver disease, diabetes mellitus, autoimmune disease, neutropenia, abdominal surgery $\leq 3$ months before onset, invasive mechanical ventilation at the time of onset, renal replacement therapy $\leq 30$ days before onset, total parenteral nutrition [TPN] at the time of onset, antibiotic therapy [for $\geq 3$ days] $\leq 30$ days before onset, antifungal therapy [for $\geq 3$ days] $\leq 30$ days before onset, immunosuppressive therapy $\leq 30$ days before onset); shock $\leq 24$ h following onset; concurrent bacteremia at onset; breakthrough candidemia; causative Candida species; source of candidemia; treatment $\leq 24 \mathrm{~h}$ following onset (appropriate antifungal therapy alone, CVC removal alone, or a combination of them [combined intervention]); and treatment $\leq 48 \mathrm{~h}$ following onset.

The primary outcome of this study was 30-day crude mortality.

\section{Definitions}

Candidemia was defined as the isolation of Candida species from at least one blood culture. Candidemia onset was defined as the time when the first positive blood culture for Candida species was drawn from the patient. Neutropenia was defined as an absolute neutrophil count $<500$ cells $/ \mathrm{mm}^{3}$. Immunosuppressive therapy was defined as the administration of corticosteroids, chemotherapy drugs, or other immunosuppressive drugs. Shock was defined as the initiation or increment of inotropes/vasopressors $\leq 24 \mathrm{~h}$ following onset to maintain a mean arterial blood pressure of $\geq 65 \mathrm{mmHg}$. Breakthrough candidemia was defined as candidemia that occurred in patients receiving antifungal agents at the time of onset for $\geq 3$ days. CVC-related candidemia was defined as the isolation of the same Candida species from blood culture and CVC tip culture. Appropriate antifungal therapy was defined as the administration of the correct dose of antifungal agent for a susceptible Candida species. Correct doses of antifungal agents were defined as follows: caspofungin, loading dose of $70 \mathrm{mg}$, then $50 \mathrm{mg}$ daily; micafungin, 100-150 mg daily; liposomal amphotericin $\mathrm{B}, 2.5-5 \mathrm{mg} / \mathrm{kg}$ daily; fluconazole, loading dose of $800 \mathrm{mg}$ (or $12 \mathrm{mg} / \mathrm{kg}$ ), then $400 \mathrm{mg}$ (or $6 \mathrm{mg} / \mathrm{kg}$ ) daily; fosfluconazole, loading dose of $800 \mathrm{mg}$ (or $12 \mathrm{mg} / \mathrm{kg}$ ) daily for 2 days, then $400 \mathrm{mg}$ (or 6 $\mathrm{mg} / \mathrm{kg}$ ) daily; and voriconazole, loading dose of $400 \mathrm{mg}$ (or $6 \mathrm{mg} / \mathrm{kg}$ ) twice daily for 2 doses, then 200-300 mg (or $3-4 \mathrm{mg} / \mathrm{kg}$ ) twice daily $[7,8]$. Antifungal susceptibility was determined using the guidelines in the Clinical and Laboratory Standard Institute document M27-S3 [9].

Candidemia occurring $>30$ days following the preceding candidemia onset was considered as a new episode. We only included the first episode of candidemia during the study period in the analyses.

\section{Microbiological procedures}

In both participating hospitals, Candida species were isolated using an automated blood culture system 
(BACT/ALERT 3D; bioMérieux, Tokyo, Japan) and identified using the VITEK 2 YST ID card (bioMérieux).

\section{Statistical analysis}

Qualitative variables were reported as frequencies and percentages. Quantitative variables were reported as means and standard deviations (SDs) when parametric, or as medians and interquartile ranges (IQRs) when nonparametric. Qualitative variables were analyzed using Fisher's exact test. Parametric data were analyzed using the $t$ test, and nonparametric data were analyzed using the Mann-Whitney $U$ test. We performed univariate and multivariate logistic regression analysis to identify factors associated with 30-day crude mortality. We entered variables significant by univariate logistic regression analysis at the $P<0.10$ level, as well as prespecified variables, into the multivariate logistic regression analysis. The following prespecified variables were selected on the basis of the results of previous studies and our clinical interest: APACHE II score $\leq 24 \mathrm{~h}$ following onset; treatment $\leq 24 \mathrm{~h}$ and $\leq 48 \mathrm{~h}$ following onset (appropriate antifungal therapy alone, CVC removal alone, or combined intervention). To assess the impact of these two different periods between the time of onset and intervention, we structured two multivariate logistic regression models. Furthermore, we conducted subgroup analyses for factors associated with mortality in patients with $\mathrm{CVC}$ related and CVC-unrelated candidemia. All statistical tests were two-tailed and $P$ values $<0.05$ were considered statistically significant.

\section{Results}

\section{Patient characteristics at candidemia onset}

We identified a total of 68 patients with a median age of 68.0 years (61.0-76.0) who met the inclusion criteria (Table 1). Of these, 47 (69\%) were males. The most common comorbidities were liver disease, diabetes mellitus, and autoimmune disease (for each, 14 [21\%] patients). Fifty-six (82\%) patients were receiving invasive mechanical ventilation at the time of onset. Within 30

Table 1 Patient characteristics at candidemia onset

\begin{tabular}{|c|c|c|c|c|}
\hline Variables & $\begin{array}{l}\text { Total cohort } \\
(n=68)\end{array}$ & $\begin{array}{l}\text { 30-day survivors } \\
(n=31)\end{array}$ & $\begin{array}{l}\text { 30-day non-survivors } \\
(n=37)\end{array}$ & $P$ value \\
\hline Male sex & $47(69.1)$ & $22(71.0)$ & $25(67.6)$ & 0.798 \\
\hline Age (years) & $68.0(61.0-76.0)$ & $68.0(58.0-76.0)$ & $68.0(63.0-76.0)$ & 0.782 \\
\hline Time from hospital admission to onset (days) & $24.5(8.0-46.5)$ & $20.0(6.0-42.0)$ & $26.0(9.0-47.0)$ & 0.479 \\
\hline APACHE II score (points) & $21.0(18.0-26.0)$ & $19.0(13.0-24.0)$ & $23.0(19.0-27.0)$ & 0.003 \\
\hline \multicolumn{5}{|l|}{ Comorbidities and prior treatment exposure } \\
\hline Solid organ malignancy* & $11(16.2)$ & $6(19.4)$ & $5(13.5)$ & 0.531 \\
\hline Hematological malignancy* & $2(2.9)$ & $0(0.0)$ & $2(5.4)$ & 0.496 \\
\hline Solid organ transplantation & $4(5.9)$ & $1(3.2)$ & $3(8.1)$ & 0.620 \\
\hline Hematopoietic stem cell transplantation & $1(1.5)$ & $0(0.0)$ & $1(2.7)$ & 1.000 \\
\hline Liver disease & $14(20.6)$ & $6(19.4)$ & $8(21.6)$ & 1.000 \\
\hline Diabetes mellitus & $14(20.6)$ & $4(12.9)$ & $10(27.0)$ & 0.229 \\
\hline Autoimmune disease & $14(20.6)$ & $7(22.6)$ & $7(18.9)$ & 0.769 \\
\hline Neutropenia $\left(<500\right.$ cells $\left./ \mathrm{mm}^{3}\right)$ & $2(2.9)$ & $0(0.0)$ & $2(5.4)$ & 0.496 \\
\hline Abdominal surgery** & $18(26.5)$ & $7(22.6)$ & $11(29.7)$ & 0.587 \\
\hline Invasive mechanical ventilation & $56(82.4)$ & $23(74.2)$ & $33(89.2)$ & 0.124 \\
\hline Renal replacement therapy ${ }^{\dagger}$ & $23(33.8)$ & $7(22.6)$ & $16(43.2)$ & 0.122 \\
\hline Total parenteral nutrition & $43(63.2)$ & $18(58.1)$ & $25(67.6)$ & 0.458 \\
\hline Antibiotic therapy (for $\geq 3$ days) ${ }^{+}$ & 65 (95.6) & $30(96.8)$ & $35(94.6)$ & 1.000 \\
\hline Antifungal therapy (for $\geq 3$ days) ${ }^{\dagger}$ & $6(8.8)$ & $2(6.5)$ & $4(10.8)$ & 0.681 \\
\hline Immunosuppressive therapy ${ }^{\dagger}$ & $26(38.2)$ & $9(29.0)$ & $17(46.0)$ & 0.211 \\
\hline Shock & $42(61.8)$ & $17(54.8)$ & $25(67.6)$ & 0.324 \\
\hline Concurrent bacteremia & $22(32.4)$ & $10(32.3)$ & $12(32.4)$ & 1.000 \\
\hline Breakthrough candidemia & $6(8.8)$ & $2(6.5)$ & $4(10.8)$ & 0.681 \\
\hline
\end{tabular}

Values are given as $n$ (\%) or median (interquartile range). APACHE acute physiology and chronic health evaluation.

${ }^{*} \leq 1$ year before onset

** $\leq 3$ months before onset

${ }^{\dagger} \leq 30$ days before onset 
days prior to onset, 65 (96\%) patients had received antibiotics for $\geq 3$ days.

\section{Causative Candida species and source of infection}

The most common causative Candida species was Candida albicans (40 [59\%] patients), followed by Candida glabrata (17 [25\%] patients) (Table 2). Two causative Candida species were isolated simultaneously in six (9\%) patients. With regard to the source of infection, CVCrelated candidemia was the most frequent (30 [44\%] patients), followed by intra-abdominal infection (10 [15\%] patients).

\section{Management of candidemia}

For initial antifungal treatment (including inappropriate antifungal treatment), micafungin was most frequently used antifungal agent (in 41 [60\%] patients), followed by liposomal amphotericin B (in 11 [16\%] patients) (Table 3). Within $48 \mathrm{~h}$ following onset, 9 (13\%) patients received appropriate antifungal therapy alone, $18(27 \%)$ patients had CVC removal alone, 16 (24\%) patients received combined intervention, whereas 25 (37\%) patients received either no treatment or inappropriate antifungal therapy alone. In addition, no patient received source control other than $\mathrm{CVC}$ removal $\leq 48 \mathrm{~h}$ following onset.

\section{Outcome and factors associated with mortality}

Thirty-day crude mortality was $54 \%$ (37 patients). In univariate analysis for mortality, the following two variables showed $P$ values $<0.10$ : APACHE II score $\leq 24 \mathrm{~h}$ following onset (1-point increments) (odds ratio [OR] $1.14,95 \%$ confidence interval $[\mathrm{CI}] 1.04-1.25, P=0.005$ ); and renal replacement therapy $\leq 30$ days before onset (OR 2.61, 95\% CI 0.90-7.57, $P=0.077$ ). In multivariate logistic regression analysis, only APACHE II score (1point increments) was independently associated with higher 30-day crude mortality both in model 1 (OR 1.14, 95\% CI 1.03-1.25, $P=0.007$ ) and in model 2 (OR 1.14, 95\% CI 1.04-1.26, $P=0.008$ ) (Table 4). Other variables, including treatment $\leq 24 \mathrm{~h}$ and $\leq 48 \mathrm{~h}$ following onset, did not significantly influence mortality.

\section{Subgroup analysis in patients with CVC-related/-unrelated candidemia}

Mortality rates did not differ significantly between patients with CVC-related candidemia (30 patients) and CVC-unrelated candidemia (38 patients) $(50 \%$ vs $58 \%, P$ $=0.625$ ). Univariate logistic regression analysis for mortality showed that the following host-related factors were significantly associated with poor 30-day survival: renal replacement therapy $\leq 30$ days before onset (OR 12.25, 95\% CI 1.27-118.36, $P=0.030$ ) in CVC-related candidemia; APACHE II score $\leq 24 \mathrm{~h}$ following onset (1-point increments) (OR 1.17, 95\% CI 1.03-1.33, $P=0.017$ ); and TPN at onset (OR 4.37, 95\% CI 1.07-17.79, $P=0.039$ ) in CVC-unrelated candidemia. There was no significant association between early intervention (i.e., appropriate antifungal therapy and/or CVC removal) and mortality in the two subgroups. Due to the small sample size, we could not conduct multivariate logistic regression analysis among the subgroups.

\section{Discussion}

In this bicentric observational study, we investigated the characteristics and impact of host- and early treatmentrelated factors in ICU patients with candidemia. We found that APACHE II score $\leq 24 \mathrm{~h}$ following candidemia onset was the only parameter independently

Table 2 Causative Candida species and source of infection

\begin{tabular}{|c|c|c|c|c|}
\hline Variables & Total cohort $(n=68)$ & 30-day survivors $(n=31)$ & 30-day non-survivors $(n=37)$ & $P$ value \\
\hline \multicolumn{5}{|c|}{ Causative Candida species* } \\
\hline Candida albicans & $40(58.8)$ & $19(61.3)$ & $21(56.8)$ & 0.806 \\
\hline Candida glabrata & $17(25.0)$ & $6(19.4)$ & $11(29.7)$ & 0.405 \\
\hline Candida parapsilosis & $8(11.8)$ & $3(9.7)$ & $5(13.5)$ & 0.719 \\
\hline Candida tropicalis & $7(10.3)$ & $3(9.7)$ & $4(10.8)$ & 1.000 \\
\hline Candida krusei & $1(1.5)$ & $1(3.2)$ & $0(0.0)$ & 0.456 \\
\hline Others & $1(1.5)$ & $0(0.0)$ & $1(2.7)$ & 1.000 \\
\hline \multicolumn{5}{|l|}{ Source of infection } \\
\hline CVC-related & $30(44.1)$ & $15(48.4)$ & $15(40.5)$ & 0.625 \\
\hline Intra-abdominal & $10(14.7)$ & $4(12.9)$ & $6(16.2)$ & 0.745 \\
\hline Skin and soft tissue & $4(5.9)$ & $3(9.7)$ & $1(2.7)$ & 0.324 \\
\hline Cardiovascular & $1(1.5)$ & $0(0.0)$ & $1(2.7)$ & 1.000 \\
\hline Others or unknown & $23(33.8)$ & $9(29.0)$ & $14(27.8)$ & 0.607 \\
\hline
\end{tabular}

Values are given as $n$ (\%). CVC central venous catheter

*Two causative Candida species were isolated simultaneously in $6(8.8 \%)$ patients 
Table 3 Management of candidemia

\begin{tabular}{|c|c|c|c|c|}
\hline Variables & Total cohort $(n=68)$ & 30-day survivors $(n=31)$ & 30-day non-survivors $(n=37)$ & $P$ value \\
\hline \multicolumn{5}{|l|}{ Initial antifungal agent* } \\
\hline Micafungin & $41(60.3)$ & $19(61.3)$ & $22(59.5)$ & 1.000 \\
\hline Liposomal amphotericin B & $11(16.2)$ & $6(19.4)$ & $5(13.5)$ & 0.531 \\
\hline Fluconazole & $7(10.3)$ & $2(6.5)$ & $5(13.5)$ & 0.442 \\
\hline Voriconazole & $3(4.4)$ & $2(6.5)$ & $1(2.7)$ & 0.588 \\
\hline None during candidemia & $7(10.3)$ & $2(6.5)$ & $5(13.5)$ & 0.442 \\
\hline \multicolumn{5}{|l|}{ Treatment $\leq 24 \mathrm{~h}$ following onset } \\
\hline Appropriate antifungal therapy alone & $4(5.9)$ & $3(9.7)$ & $1(2.7)$ & 0.324 \\
\hline CVC removal alone & $19(27.9)$ & $9(29.0)$ & $10(27.0)$ & 1.000 \\
\hline Combined intervention & $5(7.4)$ & $2(6.5)$ & $3(8.1)$ & 1.000 \\
\hline \multicolumn{5}{|l|}{ Treatment $\leq 48 \mathrm{~h}$ following onset } \\
\hline Appropriate antifungal therapy alone & $9(13.2)$ & $3(9.7)$ & $6(16.2)$ & 0.494 \\
\hline CVC removal alone & $18(26.5)$ & $8(25.8)$ & $10(27.0)$ & 1.000 \\
\hline Combined intervention & $16(23.5)$ & $9(29.0)$ & $7(18.9)$ & 0.396 \\
\hline
\end{tabular}

Values are given as $n$ (\%). CVC central venous catheter

*Including antifungal agents used in inappropriate antifungal therapy

associated with death, and that none of the therapeutic interventions (including early empiric antifungal therapy and/or early CVC removal) had a significant impact on mortality. In subgroup analysis, we also found that the other two host-related factors (i.e., renal replacement therapy $\leq 30$ days before onset in patients with CVCrelated candidemia and TPN at onset in CVC-unrelated candidemia) but not early treatment-related factors were significantly associated with mortality in univariate logistic regression analyses, which supported the primary results.

According to the current published guidelines, prompt antifungal therapy and CVC removal are encouraged $[8$,
10]. There have been several positive results regarding the effect of early intervention on mortality in ICU patients with candidemia $[4,5,11]$. One study in Spanish ICUs reported that combined intervention (i.e., appropriate antifungal therapy and CVC removal) $\leq 48 \mathrm{~h}$ following onset was significantly associated with lower early ( $\leq 7$ days) crude mortality, but not with late $(8-30$ days) crude mortality [5]. Another study in Indian ICUs demonstrated a significant association between early intervention and 30-day crude mortality [4]. Surprisingly, the results from the present study are not in line with these findings. Differences in patients' age, background, proportion of CVC placement, or severity of

Table 4 Multivariate logistic regression analysis of risk factors for 30-day mortality

\begin{tabular}{|c|c|c|c|c|}
\hline \multirow[t]{2}{*}{ Variables } & \multicolumn{2}{|l|}{ Model 1} & \multicolumn{2}{|l|}{ Model 2} \\
\hline & OR $(95 \% \mathrm{Cl})$ & $P$ value & OR $(95 \% \mathrm{Cl})$ & $P$ value \\
\hline APACHE II score (1-point increments) & $1.14(1.03-1.25)$ & 0.007 & $1.14(1.04-1.26)$ & 0.008 \\
\hline Renal replacement therapy* & $2.96(0.91-9.61)$ & 0.070 & $2.77(0.87-8.80)$ & 0.085 \\
\hline \multicolumn{5}{|l|}{ Treatment $\leq 24 \mathrm{~h}$ following onset } \\
\hline None or inappropriate antifungal therapy alone & Reference & & & \\
\hline Appropriate antifungal therapy alone & $0.23(0.02-3.12)$ & 0.267 & & \\
\hline CVC removal alone & $0.97(0.29-3.29)$ & 0.961 & & \\
\hline Combined intervention & $1.66(0.17-16.56)$ & 0.666 & & \\
\hline \multicolumn{5}{|l|}{ Treatment $\leq 48 \mathrm{~h}$ following onset } \\
\hline None or inappropriate antifungal therapy alone & & & Reference & \\
\hline Appropriate antifungal therapy alone & & & $1.06(0.17-6.50)$ & 0.948 \\
\hline Source control alone & & & $1.15(0.30-4.43)$ & 0.840 \\
\hline Combined therapy & & & $0.59(0.14-2.39)$ & 0.456 \\
\hline
\end{tabular}

APACHE acute physiology and chronic health evaluation, $\mathrm{Cl}$ confidence interval, $O R$ odds ratio 
illness among other studies and the present one might account for these discrepancies.

Conversely, and in line with findings from the present study, several studies reported no significant relationships between early intervention and mortality in ICU patients with candidemia $[2,12,13]$. These studies consistently suggested that host-related factors (e.g. comorbidities, prior treatment exposure, or APACHE II score at diagnosis) had more impact on mortality than early intervention. Compared with other patients with bacteremia, patients with candidemia are often more severely ill, receive more organ support therapies (e.g., mechanical ventilation or vasopressors), and are associated with higher mortality rates [14-16]. Therefore, findings from the present and previous studies might be indicative that early interventions in ICU patients with candidemia have less impact on mortality compared to other ICU patients with bacteremia.

We should be aware that all aforementioned studies, including the present one, were observational in design, possibly containing various biases and unmeasured potential confounders. No meta-analysis or randomized trials have yet been conducted to investigate the effect of early intervention in ICU patients with candidemia [17]. In the future, randomized studies targeting subgroups such as patients with septic shock due to candidemia could be considered, as several observational studies with positive results were derived from this population in the past $[18,19]$.

Our study has a strength in targeting patients with (1) microbiologically confirmed candidemia, (2) onset of candidemia during ICU stay, and (3) CVC in situ at the time of onset, in order to appropriately evaluate the effect of therapeutic intervention. On the other hand, this study had several limitations. Firstly, we could not assess candidemia-attributable mortality, which has been previously reported as $5-22 \%[4,11,20]$. However, there has been no accepted definition of attributable mortality and several studies even concluded that candidemia itself did not significantly increase mortality $[11,13]$. Secondly, we could not perform subgroup analysis based on causative Candida species. According to a previous study, distribution of isolated Candida species among invasive candidiasis depends on various factors such as geography, underlying disease, and prior exposure to antibiotics [21]. Further large-scale studies to assess whether clinical features and effects of therapeutic interventions depend on causative Candida species are warranted [22]. Acknowledging these strengths and limitations, our study could demonstrate no significant clinical benefit of early intervention among ICU patients with candidemia and suggested the need to conduct a meta-analysis or randomized trial that would potentially impact future clinical practice guidelines.

\section{Conclusions}

Candidemia in ICU patients is still associated with high 30-day crude mortality rates. The only predictor of death was APACHE II score $\leq 24 \mathrm{~h}$ following candidemia onset. Early empiric antifungal therapy and/or early CVC removal conferred no significant clinical benefit on survival in this patient population.

\begin{abstract}
Abbreviations
ICU: Intensive care unit; CVC: Central venous catheter; APACHE: Acute Physiology and Chronic Health Evaluation; TPN: Total parenteral nutrition; SD: Standard deviation; IQR: Interquartile range
\end{abstract}

\section{Acknowledgements}

This study was funded only by the authors' institutions.

\section{Availability of datasets and materials}

The datasets generated and analyzed during the current study are not available due to privacy concerns and institutional policy. Data extracts can be made available on reasonable request to the corresponding author.

\section{Authors' contributions}

All authors contributed to the study conception and design. NS and NF supervised the study. SO and TK collected the data. SO analyzed the data and drafted the manuscript. All authors have read and approved the final manuscript

\section{Funding}

This study was funded only by the authors' institutions.

\section{Ethics approval and consent to participate}

All data were anonymized and the requirement for informed consent was waived due to the study design. This study was approved by the institutional review board of Hiroshima University (approval number: E-746) and Kyoto Prefectural University of Medicine (approval number: ERB-C-1162).

\section{Consent for publication}

Not applicable

\section{Competing interests}

The authors declare that they have no competing interests.

\section{Author details}

${ }^{1}$ Department of Emergency and Critical Care Medicine, Graduate School of Biomedical and Health Sciences, Hiroshima University, 1-2-3 Kasumi, Minami-ku, Hiroshima 734-8551, Japan. ²Department of Pharmacy, Kyoto Prefectural University of Medicine, Kajii-cho, Kawaramachi-Hirokoji, Kamigyo-ku, Kyoto 602-8566, Japan. ${ }^{3}$ Department of Infection Control and Laboratory Medicine, Kyoto Prefectural University of Medicine, Kajii-cho, Kawaramachi-Hirokoji, Kamigyo-ku, Kyoto 602-8566, Japan.

Received: 13 February 2020 Accepted: 21 April 2020

Published online: 26 April 2020

\section{References}

1. Wisplinghoff $H$, Bischoff $T$, Tallent SM, Seifert $H$, Wenzel RP, Edmond MB. Nosocomial bloodstream infections in US hospitals: analysis of 24,179 cases from a prospective nationwide surveillance study. Clin Infect Dis. 2004;39: 309-17.

2. Charles PE, Doise JM, Quenot JP, Aube H, Dalle F, Chavanet P, et al. Candidemia in critically ill patients: difference of outcome between medical and surgical patients. Intensive Care Med. 2003;29:2162-9.

3. Kett DH, Azoulay E, Echeverria PM, Vincent JL. Extended prevalence of infection in ICU study (EPIC II) group of investigators. Candida bloodstream infections in intensive care units: analysis of the extended prevalence of infection in intensive care unit study. Crit Care Med. 2011;39:665-70.

4. Chakrabarti A, Sood P, Rudramurthy SM, Chen S, Kaur H, Capoor M, et al. Incidence, characteristics and outcome of ICU-acquired candidemia in India. Intensive Care Med. 2015;41:285-95. 
5. Puig-Asensio M, Pemán J, Zaragoza R, Garnacho-Montero J, Martín-Mazuelos $\mathrm{E}$, Cuenca-Estrella M, et al. Impact of therapeutic strategies on the prognosis of Candidemia in the ICU. Crit Care Med. 2014;42:1423-32.

6. Labelle AJ, Micek ST, Roubinian N, Kollef MH. Treatment-related risk factors for hospital mortality in Candida bloodstream infections. Crit Care Med. 2008:36:2967-72.

7. Takesue Y, Ueda T, Mikamo H, Oda S, Takakura S, Kitagawa Y, et al. Management bundles for candidaemia: the impact of compliance on clinical outcomes. J Antimicrob Chemother. 2015;70:587-93.

8. Pappas PG, Kauffman CA, Andes DR, Clancy CJ, Marr KA, Ostrosky-Zeichner L, et al. Clinical practice guideline for the management of candidiasis: 2016 update by the Infectious Diseases Society of America. Clin Infect Dis. 2016; 62:e1-50.

9. Clinical and Laboratory Standards Institute. Reference method for broth dilution antifungal susceptibility testing of yeasts; Third informational supplement. CLSI document M27-S3. Wayne, Pennsylvania: Clinical and Laboratory Standards Institute; 2008.

10. Martin-Loeches I, Antonelli M, Cuenca-Estrella M, Dimopoulos G, Einav S, De Waele JJ, et al. ESICM/ESCMID task force on practical management of invasive candidiasis in critically ill patients. Intensive Care Med. 2019;45:789-805.

11. Blot SI, Vandewoude KH, Hoste EA, Colardyn FA. Effects of nosocomial candidemia on outcomes of critically ill patients. Am J Med. 2002;113:480-5.

12. Marriott DJ, Playford EG, Chen S, Slavin M, Nguyen $Q$, Ellis $D$, et al. Determinants of mortality in non-neutropenic ICU patients with candidaemia. Crit Care. 2009;13:R115.

13. González de Molina FJ, León C, Ruiz-Santana S, Saavedra P, CAVA I Study Group. Assessment of candidemia-attributable mortality in critically ill patients using propensity score matching analysis. Crit Care. 2012;16:R105.

14. Savage RD, Fowler RA, Rishu AH, Bagshaw SM, Cook D, Dodek P, et al. The effect of inadequate initial empiric antimicrobial treatment on mortality in critically ill patients with bloodstream infections: a multi-centre retrospective cohort study. PLoS One. 2016;11:e0154944.

15. Atamna A, Eliakim-Raz N, Mohana J, Ben-Zvi H, Sorek N, Shochat T, et al. Predicting candidemia in the internal medicine wards: a comparison with gram-negative bacteremia-a retrospectives study. Diagn Microbiol Infect Dis. 2019;95:80-3.

16. Schwab F, Geffers C, Behnke M, Gastmeier P. ICU mortality following ICUacquired primary bloodstream infections according to the type of pathogen: a prospective cohort study in 937 Germany ICUs (2006-2015). PLoS One. 2018;13:e0194210.

17. Janum S, Afshari A. Central venous catheter (CVC) removal for patients of all ages with candidaemia. Cochrane Database Syst Rev. 2016;7:CD011195.

18. Kollef M, Micek S, Hampton N, Doherty JA, Kumar A. Septic shock attributed to Candida infection: importance of empiric therapy and source control. Clin Infect Dis. 2012:54:1739-46.

19. Bassetti M, Righi E, Ansaldi F, Merelli M, Trucchi C, De Pascale G, et al. A multicenter study of septic shock due to candidemia: outcomes and predictors of mortality. Intensive Care Med. 2014:40:839-45.

20. Nolla-Salas J, Sitges-Serra A, León-Gil C, Martínez-González J, León-Regidor MA, Ibánez-Lucía P, et al. Candidemia in non-neutropenic critically ill patients: analysis of prognostic factors and assessment of systemic antifungal therapy. Intensive Care Med. 1997;23:23-30.

21. Antinori S, Milazzo L, Sollima S, Galli M, Corbellino M. Candidemia and invasive candidiasis in adults: a narrative review. Eur J Intern Med. 2016;34:21-8.

22. Shorr AF, Lazarus DR, Sherner JH, Jackson WL, Morrel M, Fraser VJ, et al. Do clinical features allow for accurate prediction of fungal pathogenesis in bloodstream infections? Potential implications of the increasing prevalence of non-albicans candidemia. Crit Care Med. 2007;35:1077-83.

\section{Publisher's Note}

Springer Nature remains neutral with regard to jurisdictional claims in published maps and institutional affiliations.

Ready to submit your research? Choose BMC and benefit from:

- fast, convenient online submission

- thorough peer review by experienced researchers in your field

- rapid publication on acceptance

- support for research data, including large and complex data types

- gold Open Access which fosters wider collaboration and increased citations

- maximum visibility for your research: over $100 \mathrm{M}$ website views per year

At BMC, research is always in progress.

Learn more biomedcentral.com/submissions 